\title{
A Review of Early Displaced Maxillary Canines: Etiology, Diagnosis and Interceptive Treatment
}

\author{
George Litsas, ${ }^{1, *}$ and Ahu Acar ${ }^{2}$ \\ ${ }^{1}$ Orthodontist 2, Venizelou Str., 50100 Kozani, Greece \\ ${ }^{2}$ Faculty of Dentistry, Marmara University, Istanbul Turkey
}

\begin{abstract}
Impaction of maxillary canines is a frequently encountered clinical problem the treatment of which usually requires an interdisciplinary approach. Surgical exposure of the impacted tooth and the complex orthodontic mechanisms that are applied to align the tooth into the arch may lead to varying amounts of damage to the supporting structures of the tooth, not to mention the long treatment duration and the financial burden to the patient. Hence, it seems worthwhile to focus on the means of early diagnosis and interception of this clinical situation. In the present article, theories related with the etiology of impacted canines and predictive variables of canine impaction in the mixed dentition are reviewed with an insight into current interceptive treatment modalities.
\end{abstract}

Key Words: Early displaced canines, etiology, diagnosis, prevention.

\section{INTRODUCTION}

The orthodontic treatment of impacted maxillary canine remains a challenge to today's clinicians. The treatment of this clinical entity usually involves surgical exposure of the impacted tooth, followed by orthodontic traction to guide and align it into the dental arch. Bone loss, root resorption and gingival recession around the treated teeth are some of the most common complications [1]. Early diagnosis and intervention could save the time, expense, and more complex treatment in the permanent dentition.

Tooth impaction can be defined as the infraosseous position of the tooth after the expected time of eruption, whereas the anomalous infraosseous position of the canine before the expected time of eruption can be defined as a displacement. Most of the time, palatal displacement of the maxillary canine results in impaction [2].

The purpose of this review was to investigate the literature for articles related to etiology, diagnosis, and interceptive treatment of early displaced maxillary canines. In order to find the relevant articles a Medline search from 1966 to May of 2010 was conducted by both authors. The Medline search was based on the key word "impacted maxillary canines" and limited to the "dental journals". Studies that pertained to the prevalence, aetiology, sequels, diagnosis of impacted maxillary canines, as well as studies regarding interceptive treatment modalities were evaluated. Articles referring to craniofacial anomalies, syndromes and case reports were excluded. The periodontic and orthodontic considerations during exposure and traction of the impacted canines are also beyond the scope of this review. The final result of this search was 59 articles. Retrospective studies,

*Address correspondence to this author at the Orthodontist 2, Venizelou Str., 50100 Kozani, Greece; Tel: 00306944590196; Fax: 00302462024228; E-mail: info@orthosmile.gr randomized clinical trials as well as some reviews were included in the final list.

\section{EPIDEMIOLOGY}

The impaction of the maxillary permanent canine is a common finding of oral pathology and represents $2 \%$ of patients seeking orthodontic treatment $[3,4]$. Maxillary canine is one of the most frequently impacted teeth, second only to third molars [5] with the prevalence ranging from 0.8 to 5.2 percent depending on the population examined [6-9]. The incidence of canine impaction in the maxilla is more than twice than that in the mandible, and the ratio of palatal to buccal impaction is 8 to 1 . Eight percent of canine impactions are bilateral and it is twice more common in girls than boys [10-12].

\section{ETIOLOGY}

Primary etiological causes of maxillary canine displacement include space deficiency, disturbances in tooth eruption sequence, trauma, retention of primary canine, premature root closure, rotation of tooth buds, as well as localized pathological lesions (cysts, odontomas) [13]. The long developmental path of the maxillary canine was described by Moyers et al., [14] as: "The maxillary cuspid follows a more difficult and tortuous path of eruption than any other tooth. At the age of 3 it is high in the maxilla, with its crown directed mesially and somewhat lingually. It moves towards the occlusal plane, gradually uprighting itself until it seems to strike the distal aspect of the root of the lateral incisor. It then seems to be deflected to a more vertical position; however, it often erupts into the oral cavity with a marked mesial inclination".

Two main theories have been proposed to explain the occurrence of palatally displaced maxillary canines: the "guidance theory" and the "genetic theory". 


\section{Guidance Theory (Table 1)}

According to the guidance theory, in its simplest form, the canine lacks the guide during the eruption pathway because of extra space in the apical part of the maxilla, owing to hypoplastic or missing lateral incisor. This theory supports that palatally displaced canines are frequently found in dentitions with peg- shaped or missing laterals [7, 15-17] and spaced and late developed dentitions [4, 18]. Even if these anomalies are genetically determined, the guidance theory states that the palatal canine displacement has not a similar genetic association but occurs as a result of these local environmental disturbances [19]. Becker et al., [20] in a randomized controlled study of 19 individuals selected among consecutively treated 12.000 patients, investigated the hypothesis that palatal displacement of canines was under genetic influence. Within the same individual, each side acted as control for the other side. Even though the peg shaped or missing lateral incisors have been shown to be associated with palatal displacement of canines, the frequency of impaction was unequal in each patient with a missing lateral incisor on one side and a peg-shaped or reduced lateral incisor on the other. The connection between palatal canine displacement and normal size developing lateral incisor was studied by Becker et al., [21]. The buccal-lingual as well as the mesio-distal dimensions of all the erupted teeth mesial to the first molar were measured in 58 treated patients (37 males, 21 females) with palatally displaced canines and compared with a control group of 40 treated patients (20 males, 20 females) with normally erupted canines. They found that the only tooth that showed statistically significant $(p<0.01)$ reduction in buccal lingual dimension for both sexes was the lateral incisor. The same was true when the mesiodistal width of all permanent maxillary teeth were measured [22] in 30 patients (17 males,13 females) with buccally displaced canines without crowding, and compared with 40 (20 males, 20 females) patients with normally erupted canines. The influence of the local environment as a major cause of palatally displaced canines was supported by another retrospective study by Chaushu et al., [23]. They studied the eruption status of unerupted permanent maxillary canines of seventy-five patients with ipsilateral incisor anomalies (impacted permanent incisor) while the contralateral side was used as a control. The prevalence of displaced canines in the affected side was $41.3 \%$, significantly more than the other side $(4.7 \%)$. Furthermore, $9.5 \%$ of these canines were displaced palatally. Crowding may also play a role as an environmental cause of displacement, although Jacoby [24] in 46 and Stellzig et al., [25] in 70 palatal impacted canines found arch length sufficiency in 85 and 82 per cent respectively.

\section{Genetic Theory}

The genetic theory assigns the eruption anomaly of the upper permanent canine as a result of a developmental disturbance of the dental lamina. This theory indicates multiple evidential categories for the genetic origin of palatally impacted canines, such as familial and bilateral occurrence, sex differences, as well as an increased occurrence of other significant reciprocal dental associations such as ectopic eruption of first molars, infraocclusion of primary molars, aplasia of premolars and one third molar [26, 27]. Pirinen et al., [28] showed that 106 patients with palatally displaced canines had first and second degree relatives with some dental anomalies. Hypodontia was observed in 19 to $20 \%$ of both the first- and second-degree relatives which is 2.5 times more than the normal population prevalence. The prevalence also of missing teeth was $4.9 \%$, which again is 2.5 times more than the population prevalence. They supported that the palatally displaced canine belonged to the spectrum of dental abnormalities related to hypodontia. Peck et al., [27] examined the specificity of tooth-agenesis sites associated with the occurrence of 58 palatally displaced canines. Palatally displaced canines associated significantly $(p<0.01)$ with third molar agenesis. This type of dental anomalies belong to the so-called posterior orofacial field; a condition of increased susceptibility to developmental defects in the distal elements of a dental series. Transcription factors such as MSX1 and PAX9 which have been correlated with agenesis of molars might be involved in palatal canine displacement. Sacerdoti and Baccetti [29] in an extensive evaluation of 5000 orthodontic patients showed that unilateral palatal canine displacement correlated significantly $(\mathrm{p}<0.05)$ with aplasia of upper lateral incisors while bilateral canine displacement $(\mathrm{p}<0.05)$ with agenesis of third molars, supporting the genetic etiology of palatal canine displacement. Shalish et al., [30] concluded in a study of 99 orthodontic patients with infraoccluded primary molars, that significant associations $(\mathrm{p}<0.05)$ existed between the presence of infraocclusion and other congenital dental anomalies including palatal canine displacement.

\section{Sequelae of Maxillary Canine Impaction (Table 2)}

Even though palatally impacted teeth can cause migration of the neighbouring teeth, loss of arch length, cystic lesions and infection [13], the most important sequel of abnormal eruption path of the canine within the dentoalveolar process is root resorption of the nearby lateral incisors, jeopardizing their longevity. Unfortunately, resorption of the incisor roots is almost impossible to diagnose clinically because of lack of symptoms.

Ericson and Kurol [31] investigated the predisposing factors of adjacent permanent lateral incisors' resorption caused by ectopic eruption of maxillary canines. The subjects consisted of two groups: one with 40 cases of lateral incisor root resorption and a control group of 118 ectopic eruption cases with no lateral incisor root resorption. The mean age of the children in the two groups differed by only 0.7 of a year and ranged from 10.0 to 15.0 years, covering the normal eruption period of the maxillary canine. According to their results, when the cusp of the well developed canine was positioned mesially to the lateral incisor, the risk of complications increased three times, and an estimation of this variable showed that it accounts for approximately $40 \%$ of the variance obtained. Furthermore, the risk of resorption increased by $50 \%$ when the mesial angle eruption inclination exceeded $25^{\circ}$ as compared with the controls. The lateral incisor root resorption was 3 times more common in girls than the boys in an examined group and 6 to 5 in the control group. However, the sex factor accounts for only $16 \%$ of the variance of the score. Rimes et al., [32] in a retrospective study of 9 male and 17 female patients with a mean age of 12.5 years showed maxillary incisor root resorption in relation the 


\section{Table 1. Genetic and Guidance Theory of Palatal displaced Canines}

\begin{tabular}{|c|c|}
\hline Guidance Theory & Genetic Theory \\
\hline $\begin{array}{l}\text { Jacoby H. Am J Orthod Dentofacial Orthop 1983; 84: 125-132. } \\
85 \text { per cent of impacted canines located palatal because of maxillary excess } \\
\text { space. }\end{array}$ & $\begin{array}{l}\text { Peck L et al. Angle Orthod 1994; 64(4): 249-56. } \\
\text { The PDC appears to be a product of polygenic, multifactorial inheritance } \\
\text { because of concomitant occurrence with other dental anomalies, sex and } \\
\text { populations differences, site specificity and familial tendency. }\end{array}$ \\
\hline $\begin{array}{l}\text { There is a direct cause and effect relationship between the peg shape or } \\
\text { missing laterals and PDCs. }\end{array}$ & $\begin{array}{l}\text { Peck S et al. Angle Orthod 1996; 66: 473-76. } \\
\text { In PDCs subjects, the rate for associated third molar agenesis is twice the } \\
\text { normal rate, while lateral incisor agenesis was slightly above of no statisti- } \\
\text { cal significance. Site-specificity tooth agenesis associated with PDCs. }\end{array}$ \\
\hline $\begin{array}{l}\text { Zilberman Y et al. Eur J Orthod 1990; 12: 135-39. } \\
\text { PDCs occur in families including small and late developed lateral incisors. }\end{array}$ & $\begin{array}{l}\text { Pirinen S et al. J Dent Res 1996; 75: 1742-46. } \\
\text { Increased prevalence of PDCs and congenital missing permanent teeth in } \\
\text { the family group. The PDCs belong to the spectrum of dental abnormalities } \\
\text { related to hypodontia. }\end{array}$ \\
\hline $\begin{array}{l}\text { Stellzig A et al. Fortschr Kieferorthop 1994; 55: 97-103. } \\
\text { In } 35 \% \text { of the cases there is a correlation between peg shaped laterals and } \\
\text { PDCs. }\end{array}$ & $\begin{array}{l}\text { Baccetti T. Angle Orthod 1998; 68: 267-74. } \\
\text { Significant associations were found among i) aplasia of second premolars } \\
\begin{array}{l}\text { ii) small size of maxillary lateral incisors iii) infraocclusion of primary } \\
\text { molars and iv) PDCs, suggesting a common genetic origin for these condi- } \\
\text { tions. }\end{array}\end{array}$ \\
\hline $\begin{array}{l}\text { Mossey PA et al. Br J Orthod 1994; } 21: 169-74 . \\
\text { There is a weak relationship between peg shape or missing laterals and } \\
\text { PDCs. }\end{array}$ & $\begin{array}{l}\text { Shapira J et al. Angle Orthod 2000; 70: 290-6. } \\
\text { High prevalence of third molar agenesis, canine impaction and maxillary } \\
\text { canine/first premolar transposition. }\end{array}$ \\
\hline $\begin{array}{l}\text { Becker A et al. Clin Orthod Res 1999; 2: 62-6. } \\
\text { PDCs is not under genetic control but local environmental factors involved } \\
\text { in their impaction }\end{array}$ & $\begin{array}{l}\text { Peck S et al. Am J Orthod Dentofacial Orthop 2002; 122: 657-60. } \\
\text { Transcription factors such as MSX1 and PAX9, which have been associ- } \\
\text { ated with agenesis of molars, might be involved in the genetic control of } \\
\text { PDCs. }\end{array}$ \\
\hline $\begin{array}{l}\text { Becker A and Chaushu S. Am J Orthod Dentofacial Orthop 2000; 117: 657- } \\
62 \\
\text { Delayed dental development is another cause of PDCs. }\end{array}$ & $\begin{array}{l}\text { Leifert S, Jonas IE. J Orofac Orthop 2003; 64: 108-120. } \\
\text { The PDCs is significantly higher in patients with peg shape or congenital } \\
\text { aplasia of upper lateral incisors, impacted and congenitally missing teeth } \\
\text { and deep bite. }\end{array}$ \\
\hline $\begin{array}{l}\text { Becker A et al. Eur J Orthod 2002; 24: 313-18. } \\
\text { There is a dimensional reduction in the maxillary teeth of patients with } \\
\text { PDCs. }\end{array}$ & $\begin{array}{l}\text { Sacerdoti R and Baccetti T. Angle Orthod 2004; 74: 725-32. } \\
\text { Unilateral PDC was associated with aplasia of upper lateral incisors, } \\
\text { whereas bilateral PDC was associated with aplasia of third molars. } \\
\text { Increased prevalence in deep bite cases }\end{array}$ \\
\hline $\begin{array}{l}\text { Chaushu S et al. Am J Orthod Dentofacial Orthop 2003; 124:144-50. } \\
\text { Environmental factors involved in the impaction of maxillary central }\end{array}$ & $\begin{array}{l}\text { Shalish M et al. Angle Orthod 2010; 80: 440-5. } \\
\text { Statistically significant associations were observed between the presence of } \\
\text { infraocclusion and the occurrence of tooth agenesis, microdontia of } \\
\text { maxillary lateral incisors, PDC, and distal angulation of second } \\
\text { mandibular molars. }\end{array}$ \\
\hline
\end{tabular}


incisor and the eruption path of the ipsilateral maxillary canine.

Table 2. Root Resorption and Palatal Displaced Canines

\begin{tabular}{|l|l|}
\hline $\begin{array}{l}\text { Ericson S, Kurol J. Am J Orthod Dentofacial Orthop 1988; 91: 483-92. } \\
\begin{array}{l}\text { Cases with lateral incisor root resorption showed a more advanced dental } \\
\text { development, a more medial canine position, and more mesial horizontal } \\
\text { path of eruption than that of the control cases. }\end{array}\end{array}$ & $\begin{array}{l}\text { Root resorption of the incisors is often diagnosed late and underestimated } \\
\text { by the clinicians. }\end{array}$ \\
\hline $\begin{array}{l}\text { Ericson S, Kurol J. Angle Orthod 2000; 70: } 415-23 . \\
\begin{array}{l}\text { CT images increased the detection of root resorptions on incisors 48\%. It is } \\
\text { a more common phenomenon than previously believed. }\end{array}\end{array}$ & $\begin{array}{l}\text { Liu DG } \text { et al. Oral Surg Oral Med Oral Path Oral Radiol Endod 2008; 105: } \\
91-8 .\end{array}$ \\
$\begin{array}{l}\text { In 27.2\% of lateral and 23.4\% of central incisors. } \\
\text { Alqerban A et al. Am J Orthod Dentofacial Orthop 2009; 136: 764-5. }\end{array}$ & Haney E et al. Am J Orthod Dentofacial Orthop 2010; 137: 590-97. \\
$\begin{array}{l}\text { CBCT could detect slight and severe root cavities much better than pano- } \\
\text { ramic radiographs. }\end{array}$ & $\begin{array}{l}\text { They showed a 37\% disagreement in the perception of root resorption of the } \\
\text { adjacent teeth between the 2D and 3D images. }\end{array}$ \\
\hline
\end{tabular}

presence of a displaced canine. There were a total of 35 resorbed teeth, 26 lateral and 9 central incisors, and these were related to 32 displaced canines. They concluded that the problem is often diagnosed late both in relation to the patient's age and to the extent of resorption present. Seems that resorption on the roots of maxillary incisors due to impaction of the maxillary canines is a more common phenomenon than previously believed.

Ericson and Kurol [33] analyzed the extent and prevalence of root resorption of maxillary incisors related to maxillary canine displacement in 107 children, 39 boys and 68 girls (mean 12.5 years), with 156 ectopically and 58 normally erupting maxillary canines. In addition to a basic clinical and intraoral radiographic investigation, a computerized tomogram (CT) of the upper alveolar bones was obtained. On the sides with normally erupting canines, the roots of only 3 lateral incisors were slightly resorbed. It was probably caused by physical contact between the incisor and the canine and by pressure from the canine as a part of the eruption process. The mid root level of lateral incisors were affected more than the apical or the cervical regions. In patients with ectopically erupting maxillary canines $48 \%$ had resorbed maxillary incisors during the eruption of the maxillary canines.

The introduction of cone beam computer tomography (CBCT) has recently allowed drawing a new and much more documented light on root resorption as a sequel of canine displacement. Liu et al., [34] using CBCT images in 210 impacted maxillary canines found root resorption in $27.2 \%$ of lateral and $23.4 \%$ of central incisors. Ninety three per cent of these resorptions occurred when the impacted canines were in close contact with the incisors, indicating that incisor resorption is a common phenomenon in impacted canine patients. Alqerban et al., [35] used the cadaver skull of a child in the early mixed dentition period in order to compare the accuracy of conventional panoramic radiographic imaging and CBCT in the detection of simulated canine-induced root resorption lesions in maxillary lateral incisors. They showed that CBCT could detect slight and severe root cavities much better than panoramic radiographs $(\mathrm{p}<0.05)$. Haney et al., [36] in a prospective study of 25 impacted maxillary canines, compared the traditional 2-dimensional (2D) images such as panoramic, occlusal, and periapical radiographs to CBCT images. They found a $37 \%$ disagreement among the judges in the perception of root resorption of the adjacent teeth between the $2 \mathrm{D}$ and $3 \mathrm{D}$ images. The clinicians' confidence of accuracy of diagnosis and treatment plan was statistically higher for CBCT images ( $\mathrm{p}<0.001)$.

\section{PREDICTIVE VARIABLES IN MIXED DENTITION}

\section{I) Clinical Evaluation}

The most critical point in the prevention of possible maxillary canine impaction is the ability to recognize the tooth displacement early and to predict the subsequent failure of eruption. The average age when a maxillary canine should erupt is 13 years in boys and 12 years and 3 months in girls $[13,14]$. So, the ability to diagnose canine displacement in the early mixed dentition (average age of 8 years) and to prevent impaction of the canine would be extremely useful for the clinician. It has been postulated that some kind of genetically controlled interrelationship may exist for some of these coincidental dental anomalies, as evidenced by their frequency of association. The best time to begin assessing 
Table 3. Maxillary Width and Dentofacial Characteristics of Palatal Displaced Canines

\begin{tabular}{|c|c|}
\hline Maxillary Width and PDC & Dentofacial Characteristics and PDC \\
\hline PDCs associated with decreased width in the anterior maxillary area. & $\begin{array}{l}80 \% \text { of patients with impacted canines have horizontal facial growth } \\
\text { pattern. }\end{array}$ \\
\hline Stellzig A et al. Fortschr Kieferorthop 1994; 55: 97-103. & Basdra EK et al. Eur J Orthod 2001; 23: 145-151. \\
\hline $82 \%$ of the PDCs have maxillary width excess. & $\begin{array}{l}\text { No statistical differences between the Class III and the Class II division } 1 \\
\text { malocclusions and PDCs. }\end{array}$ \\
\hline $\begin{array}{l}\text { Langberg BJ, Peck S. Am J Orthod Dentofacial Orthop 2000; 118: 220-23. } \\
\text { No statistical differences between two groups both in the anterior and the } \\
\text { posterior maxillary width. }\end{array}$ & $\begin{array}{l}\text { Sacerdoti R and Baccetti T. Angle Orthod 2004; } 74: 725-32 \\
60 \% \text { of the patients with PDCs have a low angle vertical growth pattern }\end{array}$ \\
\hline Al Nimri K and Gharaibeh T. Eur J Orthod 2005; 27: 461-5. & Al Nimri K and Gharaibeh T. Eur J Orthod 2005; 27: 461-5. \\
\hline $\begin{array}{l}\text { The transverse arch dimension was significantly wider in the PDCs pa- } \\
\text { tients. }\end{array}$ & $\begin{array}{l}\text { PDC occurred most frequently in subjects with a Class II Division II mal- } \\
\text { occlusion (44\%). }\end{array}$ \\
\hline Sambataro S et al. Angle Orthod 2005; 75: 28-34. & $\begin{array}{l}\text { Lüdicke G } \text { et al. Incisor inclination-risk factor for palatally-impacted } \\
\text { canines. J Orofac Orthop 2008; } 69 \text { 357-64. }\end{array}$ \\
\hline $\begin{array}{l}\text { The closer the canine crown is to the mid-sagittal line and the larger the } \\
\text { posterior part of hemimaxilla in the PA analysis the higher the probability } \\
\text { of eruption disturbance. }\end{array}$ & $45 \%$ of patients with PDCs had Class II, Division II malocclusion \\
\hline
\end{tabular}

potential impaction is during the early mixed dentition period, because the early diagnosis of one dental anomaly may indicate an increased risk for later appearance of others [6, 27]. Recognition of tooth disturbances in early mixed dentition such as peg shape or missing lateral incisors, enamel hypoplasia, aplasia of second premolars, and infraocclusion of primary molars could be predictors of possible canine impaction [3, 30, 27]. The mesiodistal crown dimensions of the maxillary and mandibular incisors have been reported also to be significantly smaller in patients with palatal canine displacement, having a valuable prognostic factor in mixed dentition period $[37,38]$.

\section{II) Maxillary Width (Table 3)}

One of the most common malocclusions in the primary (12\%) and mixed dentition (7.2\%) period is a maxillary transverse deficiency [39]. Mc Connell et al., [40] implicated a transverse maxillary deficiency in the anterior portion of the dental arch as a local cause for palatal canine displacement. Inter-molar and inter-canine widths were recorded in 57 patients with 81 impacted maxillary canines and in 103 patients with normally erupted canines that served as a con- trol group. Their results demonstrated statistically significant differences $(p<0.05)$ in the maxillary width between the two groups, particularly in the anterior portion of the maxilla. However, the authors did not differentiate the buccal canine ectopia from palatal canine impaction, which is considered to be a completely different entity [24]. Langberg and Peck [3] investigated the pre-treatment arch widths of 10 males and 21 females in the permanent dentition with palatally displaced canines, and compared them to the arch widths of an unaffected group of orthodontic patients with the same age and sex distribution. They couldn't record any statistical differences between two groups both in the anterior and the posterior maxillary width. These findings, according to the authors, explain the non-extraction, non-expansion treatment protocol in most of the patients with palatal canine impaction. Al-Nimri and Gharaibeh [41] investigated the occlusal features that could contribute to the aetiology of palatal maxillary canine impaction. Pre-treatment dental casts of 34 patients (mean age $17.7 \mathrm{yrs}$ ) with unilateral palatal canine impaction were compared to randomly selected pre-treatment dental casts of patients of the same age, gender and type of malocclusion. The transverse arch dimension was significantly wider in the impaction group than in the comparison 
group $(\mathrm{P}<0.01)$. They failed to find any statistically significant difference $(\mathrm{P}>0.05)$ in the mesiodistal width of maxillary teeth between the palatal canine impaction group and their matched controls, implying that the presence of excess palatal width may contribute to the aetiology of canine impaction. Sambataro et al., [42] analysed the posterioranterior radiographs of 43 untreated subjects, 22 males and 21 females (mean age 8yrs and 5 months) in order to identify a model for early prognosis of the maxillary canine impaction. All the patients were re-examined 5 yrs and 11 months later and they were divided into two groups: the impacted and non-impacted maxillary canine group. Discriminant analysis (power $=95.3 \%$ ) indicated that the closer the canine crown is to the mid-sagittal line and the larger the posterior part of hemimaxilla in the anterior-posterior analysis the higher the probability of eruption disturbance. A prognostic formula was introduced to identify eruption disturbances of the upper canine at an early developmental stage. However, because of the additional radiation exposure, the use of the anterior-posterior radiography could be suggested in the early mixed dentition only in those patients showing tooth anomalies which associated with a higher prevalence of canine impaction. Schindel and Duffy [43] randomly selected the pre-treatment records of 84 orthodontic patients (mean age $9.5 \mathrm{yrs}$ ) with a maxillary transverse deficiency, and of a control group of 100 orthodontic patients (9.9 yrs) without transverse discrepancy. They showed a significantly $(\mathrm{p}<0.001)$ higher prevalence of unilateral canine impaction in the maxillary deficiency group compared to the control group. However, patients with maxillary deficiency did not have a greater likelihood ( $p>05)$ of having canine impaction than did the patients without maxillary deficiency.

\section{III) Dentofacial Characteristics (Table 3)}

Basdra et al., [44] investigated the relationship between different malocclusions and tooth anomalies including the canine impaction. Two-hundred Class III (110 females and 90 males) and 215 Class II Division 1 (101 females and 114 females) patients were examined for the presence of congenital tooth anomalies such as maxillary incisor hypodontia, maxillary canine impaction, transpositions, supernumerary teeth, and tooth agenesis. Canine impaction was recorded in 9\% of Class III subjects, and in 3.3\% of Class II Division 1 subjects. However, they did not differentiate the palatal from buccal canine impaction which are different clinical situations. The authors stated that both malocclusions showed patterns of congenital tooth anomalies similar to those observed in the general population. When the occurrence rate of all congenital tooth anomalies was compared between the two malocclusions, Class III subjects showed significantly higher rates $(p<0.05)$. Al-Nimri and Gharaibeh [42] reported that palatal canine impaction occurred most frequently in subjects with a Class II Division II malocclusion (44 percent). Ludicke et al., [45] evaluating the panoramic radiographs, cephalograms and pretreatment study models of 199 patients (12.7 yrs) with impacted canines, found that $45 \%$ of the patients had Class II, Division II malocclusion. This heritable malocclusion associated with an increased transverse dimension of the upper arch, deep bite, upright and small incisors could be regarded as a risk factor for canine impaction [27].

\section{IV) Radiographic Evaluation (Table 4)}

The prognosis of displaced canines in mixed dentition period can be assessed accurately only when the exact position of the tooth is known. Three variables visible on panoramic radiographs have been proposed: I) angle measured between the long axis of the impacted canine and the midline. II) distance between the canine cusp tip and the occlusal plane (from the first molar to the incisal edge of the central incisor) and III) the sector where the cusp of the impacted canine is located [31]. Lindauer et al., [46] carried out a retrospective study of 41 impacted canines $(12 \pm 1 \mathrm{yrs})$ and found that $78 \%$ exhibited overlapping with the lateral incisor. In contrast, they found overlapping in only $4 \%$ of the 71 control canines that did not develop impaction, concluding that such relations detected in panoramic radiographs during the mixed dentition period constitute a prognostic sign of canine impaction. Fernandez et al., [47] in a retrospective study of 554 maxillary canines in children between 4 and 12 years old, studied the eruption pattern of upper canine, in terms of its inclination and relation to the lateral incisor on the basis of panoramic radiographic records. When the lateral incisor is not yet fully developed, panoramic radiographs show $67 \%$ overlapping of the canine and lateral incisor. In contrast, when lateral incisor development is complete, only $11 \%$ of the subjects show some degree of overlapping. According to the authors, the overlapping of the canine and lateral incisor can be considered as a sign of early canine displacement after the incisor has completed its root development. Warford et al., [48] investigated the sector location and the angulations from panoramic radiographs and showed that impacted canines will overlap the adjacent lateral incisor in $82 \%$ of cases. Regression analysis determined that once the canine overlaps the midline of the lateral incisor, there is a greater chance (0.87) of impaction. The sector location in panoramic radiography provides the greater influence on the prediction of impaction, with angulations adding little supplementary predictive value [49].

The PA radiograph has been suggested as another option to detect early canine displacement [42]. At the age of 8, the maxillary canines should have medial inclination with crowns below the lateral border of the nasal cavity and the roots lateral to the border of the nasal cavity. Some parameters such as intercanine width, size of the follicle, symmetry and width of the nasal cavity might be associated with increased probability of upper canine impaction. It was suggested that PA technique is a useful tool to identify the spatial position of the canine in the early mixed dentition period. When preformed properly, the frontal headfilm presents the anterior area of the face with a minimal amount of distortion. However, because of the extra radiation exposure, it is recommended in those patients presenting with other tooth anomalies that associated with a higher prevalence of canine impaction [50].

Today, clinicians are beginning to appreciate the advantages that the third dimension gives to clinical diagnosis and treatment planning. Although the cone beam computed tomography principle has been in use for the last twenty years, only recently have affordable systems become commercially available. Walker et al., [51] carried out a study on $27 \mathrm{im}$ pacted canines from 19 patients ( 15 female, 4 male) in order 
Table 4. Radiographic Evaluation and Prevention of Impaction

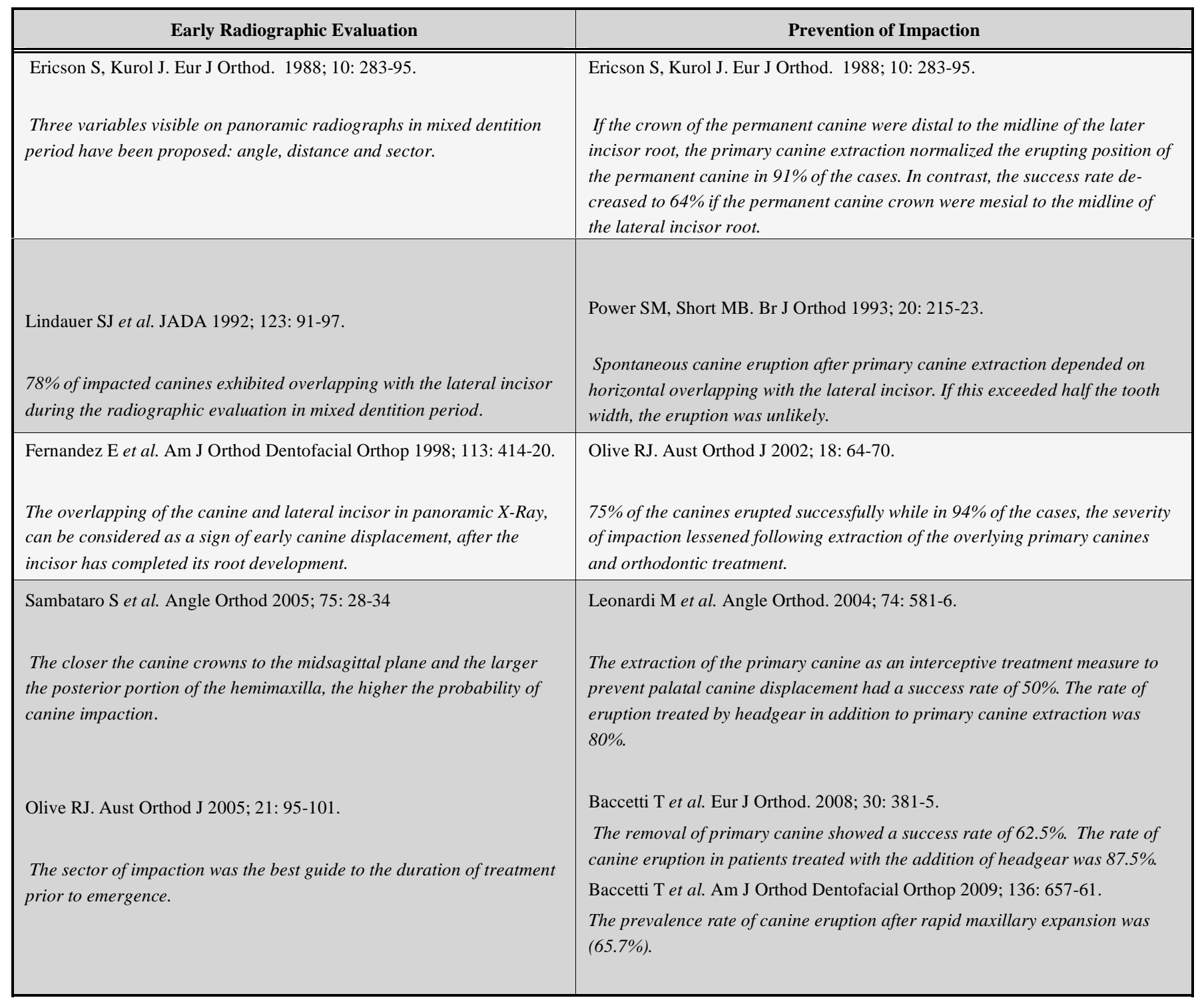

to describe the spatial relationship of impacted canines by CBCT images. It was supported that CBCT provides elements for the impacted teeth such as the size of follicle, the amount of the bone covering the tooth, buccal or palatal position and 3D proximity of adjacent teeth, which are advantageous in the management of impacted canines. Haney et al., [36] comparing the traditional 2D images to CBCT images in patients with maxillary impacted canines, found a $21 \%$ disagreement in the mesio-distal location and $16 \%$ in the labial-palatal position of the impaction. However, even if the effective radiation dose reduced by $98 \%$ compared with conventional CT systems, it remains 4 to 15 times greater than that of a single panoramic radiograph [49]. As Kokich [52] stated "will the benefit that I gain from this scan outweigh the potential risk to the patient? The responsibility is ours".

\section{Interceptive Treatment (Table 4)}

The extraction of primary canine, in the late mixed dentition period, as an interceptive treatment to prevent perma- nent canine impaction has been supported on the basis of the assumption that the persistence of the primary tooth would represent a mechanical obstacle for the emergence of the permanent tooth [53, 54]. Ericson and Kurol [10] prospectively examined 35 children 10-13 years old and found 78 per cent success in terms of rate and time (6-12 months) of spontaneous eruption of permanent canines after the extraction of primary ones. If no improvement was seen in12 months after the extraction of primary canine, then none could be expected. If the crown of the permanent canine were distal to the midline of the later incisor root, the primary canine extraction normalized the erupting position of the permanent canine in $91 \%$ of the cases. In contrast, the success rate decreased to $64 \%$ if the permanent canine crown were mesial to the midline of the lateral incisor root. The percentage decreased to 62 per cent, in a 2 year longitudinal investigation of children (11.4yrs) by Power and Short [2], suggesting that spontaneous canine eruption depended on horizontal overlapping with the lateral incisor. If this exceeded half the tooth width, the eruption was unlikely. The 
authors recommended clinical and radiographic re-evaluation every 6 months, but if the patient exceeds 13 years of age alternative treatment modalities should be considered. Olive [37] carried out a study of 28 children (13.5 years) with 32 palatally impacted canines in order to determine the success rate of canine eruption without surgical intervention. The primary canines were extracted and orthodontic treatment with fixed appliances to create space for permanent canines was deferred for at least six months if an impacted canine was the main reason for treatment, otherwise treatment was commenced according to the needs of the patient. $75 \%$ of the canines erupted successfully while in $94 \%$ of the cases, the severity of impaction lessened following extraction of the overlying primary canines and orthodontic treatment. Leonardi et al., [55] in a prospective randomized clinical trial of 46 subjects with 62 palatally displaced canines evaluated the effectiveness of extraction of the primary canines alone and in association with the use of a cervical pull headgear. The extraction of the primary canine as an interceptive treatment measure to prevent palatal canine displacement had a success rate of $50 \%$, which was not significantly greater than the success rate in untreated controls. On the other hand, the prevalence rate of successful eruption of the canine in subjects treated by headgear in addition to primary canine extraction was $80 \%$, a rate which is more than three times greater than the percentage of spontaneous eruption of the canine in untreated subjects. Baccetti et al., [56] in a similar study of 75 patients with 92 palatally displaced canines, found that the removal of primary canine as an interceptive procedure to prevent canine impaction showed a success rate of $62.5 \%$, which was significantly greater than the success rate in untreated controls $(36 \%)$. The authors stated that the need of adequate number of subjects in randomized clinical trials could be an explanation for the different results between the studies. The prevalence rate of successful permanent canine eruption in patients treated with the addition of headgear was $87.5 \%$. Both studies concluded that the headgear and the extraction group exhibited a significant improvement in the mesial inclination of the displaced tooth and its distance from the occlusal level. However, only the headgear group showed a significant improvement in the sector factor of impaction.

Maxillary expansion protocol as another treatment option in early mixed dentition period was suggested by Baccetti et al., [57]. Their prospective randomized clinical trial was based on Sambataro et al., [42] investigation that introduced a formula to diagnose the canine displacement at an early mixed dentition period. Sixty patients were randomly assigned to the treatment group or the control group. All the patients belonged to pre-peak period, had Class II or Class III tendency and maxillary dentoalveolar, not skeletal (Jugulare- Jugulare) constriction. The prediction of canine displacement was derived from analysis of posterior-anterior radiographs according to the method of Sambataro et al. Rapid maxillary expansion protocol was applied and according to their results the prevalence rate of successful eruption $(65.7 \%)$ in the treatment group was significantly higher $(p<0.001)$ than the control group $(13.6 \%)$. The intra-osseous improvement of canine position after rapid maxillary expansion could be the possible mechanism that involved in the favourable eruption process.

\section{CONCLUSION}

Recognition of tooth disturbances in early mixed dentition which are genetically associated with canine impaction can aid the clinicians in the early diagnosis of this clinical situation. If the displacement of the canines is detected early, the clinicians should then focus on the means of preventing a possible impaction. Extraction of deciduous canines in conjunction with the use of cervical pull headgear, and rapid maxillary expansion have been reported to be effective procedures in the interceptive treatment of maxillary canine impaction. There is an imperative need for more randomized controlled trials with adequate sample sizes to decide which treatment produces the most successful outcome. Other directions for future research could be: 1) investigation of the genetic factors that are hypothesized to influence this developmental anomaly in large clinical samples using the appropriate genotyping techniques, and 2) establishment of enhanced diagnostic criteria related to canine impactions through the use of CBCT.

\section{REFERENCES}

[1] Bishara SE, Kommer DD, McNeil MH, Montagana LN, Oesterle LJ, Youngquist HW. Management of impacted canines. Am J Orthod 1976; 69: 371-87.

[2] Power SM, Short MB. An investigation into the response of palatally displaced canines to the removal of deciduous canines and an assessment of factors contributing to a favourable eruption. $\mathrm{Br} \mathrm{J}$ Orthod 1993; 20: 215-23.

[3] Langberg BJ, Peck S. Adequacy of maxillary dental arch width in patients with palatally displaced canines. Am J Orthod Dentofacial Orthop 2000; 118: 220-23.

[4] Shapira J, Chaushu S, Becker A. Prevalence of tooth transposition, third molar agenesis, and maxillary canine impaction in individuals with Down syndrome. Angle Orthod 2000; 70: 290-6.

[5] Shah RM, Boyd MA, Vakil TF. Studies of permanent tooth anomalies in 7886 Canadian individuals. J Can Dent Assoc 1978; 44: 2624.

[6] Baccetti, T. A controlled study of associated dental anomalies. Angle Orthod 1998; 68: 267-4.

[7] Brin I, Becker A, Shalhav M. Position of the maxillary permanent canine in relation to anomalous or missing lateral incisors: a population study. Eur J Orthod 1986; 8: 12-6.

[8] Chu FC, Li TK, Lui VK, Newsome PR, Chow RL, Cheung LK. Prevalence of impacted teeth and associated pathologies-a radiographic study of the Hong Kong Chinese population. Hong Kong Med J 2003; 9: 158-63.

[9] Thilander B, Jakobsson SO. Local factors in impaction of maxillary canines. Acta Odontol Scand 1968; 26: 145-68.

[10] Ericson S, Kurol J. Radiographic examination of ectopically erupting maxillary canines. Am J Orthod Dentofacial Orthop 1988; 91: 483-92.

[11] Hitchin AD. The impacted maxillary canine. Br Dent J 1956; 100: $1-14$.

[12] Dachi SF, Howell FV. A survey of 3874 routine full mouth radiographs. Oral Surg Oral Med Oral Pathol 1961; 14: 1165-9.

[13] Bishara SE. Impacted maxillary canines: a review. Am J Orthod Dentofacial Orthop 1992; 101: 159-71.

[14] Moyers RE, van der Linden FP, Riolo ML, McNamara Jr. Standards of human occlusal development. monograph 5, craniofacial growth series. Ann Arbor, Mich: Center for human growth and development, The University of Michigan: 1976.

[15] Miller BH. The influence of congenitally missing teeth on the eruption of the upper canine. Dent Pract Dent Rec 1963; 13: 497504.

[16] Mossey PA, Campell HM, Luffingham JK. The palatal canine and the adjacent lateral incisor: a study of a west of Scotland population. Br J Orthod 1994; 21: 169-74. 
[17] Zilberman Y, Cohen B, Becker A. Familial trends in palatal canines, anomalous lateral incisors, and related phenomena. Eur J Orthod 1990; 12: 135-39.

[18] Becker A, Chaushu S. Dental age in maxillary canine ectopia. Am J Orthod Dentofacial Orthop 2000; 117: 657-62.

[19] Becker A. In defense of the guidance theory of palatal canine displacement. Angle Orthod 1995; 65: 95-8.

[20] Becker A, Gillis I, Shpack N. The etiology of palatal displacement of maxillary canines. Clin Orthod Res 1999; 2: 62-6.

[21] Becker A, Sharabi S, Chaushu S. Maxillary tooth size variation in dentitions with palatal canine displacement. Eur J Orthod 2002; 24 : 313-18.

[22] Chaushu S, Bongart M, Aksoy A, Ben-Bassat Y, Becker A. Buccal ectopia of maxillary canines with no crowding. Am J Orthod Dentofacial Orthop 2009; 136: 218-23.

[23] Chaushu S, Zilberman Y, Becker A. Maxillary incisor impaction and its relationship to canine displacement. Am J Orthod Dentofacial Orthop 2003; 124:144-50.

[24] Jacoby H. The etiology of maxillary canine impactions. Am J Orthod Dentofacial Orthop 1983; 84: 125-32.

[25] Stellzig A, Basdra EK, Komposch G. The etiology of canine tooth impaction--a space analysis. Fortschr Kieferorthop 1994; 55: 97 103.

[26] Peck S, Peck L, Kataja M. Site-specificity of tooth maxillary agenesis in subjects with canine malpositions. Angle Orthod 1996; 66: 473-76.

[27] Peck S, Peck L, Kataja M. Concomitant occurrence of canine malposition and tooth agenesis: evidence of orofacial genetic fields. Am J Orthod Dentofacial Orthop 2002; 122: 657-60.

[28] Pirinen S, Arte S, Apajalahti S. Palatal displacement of canine is genetic and related to congenital absence of teeth. J Dent Res 1996; 75: 1742-46.

[29] Sacerdoti R, Baccetti T. Dentoskeletal features associated with unilateral or bilateral palatal displacement of maxillary canines. Angle Orthod 2004; 74: 725-32.

[30] Shalish M, Peck S, Wasserstein A, Peck L. Increased occurrence of dental anomalies associated with infraocclusion of deciduous molars. Angle Orthod 2010; 80: 440-5.

[31] Ericson S, Kurol J. Radiographic examination of ectopically erupting maxillary canines. Am J Orthod Dentofacial Orthop 1988; 91: 483-92.

[32] Rimes RJ, Mitchell CNT, Willmot DR. Maxillary incisor root resorption in relation to the ectopic canine: a review of 26 patients. Eur J Orthod 1997; 19: 79-84.

[33] Ericson S, Kurol J. Resorption of incisors after ectopic eruption of maxillary canines. A CT study. Angle Orthod 2000; 70: 415-23.

[34] Liu DG, Zhang WL, Zhang ZY, Wu YT, Ma XC. Localization of impacted maxillary canines and observation of adjacent incisor resorption with cone-beam computed tomography. Oral Surg Oral Med Oral Path Oral Radiol Endod 2008; 105: 91-8.

[35] Alqerban A, Jacobs R, Souza PC, Willems G. In-vitro comparison of 2 cone-beam computed tomography systems and panoramic imaging for detecting simulated canine impaction-induced external root resorption in maxillary lateral incisors. Am J Orthod Dentofacial Orthop 2009; 136: 764-5.

[36] Haney E, Gansky SA, Lee JS, et al. Comparative analysis of traditional radiographs and cone-beam computed tomography volumetric images in the diagnosis and treatment planning of maxillary impacted canines. Am J Orthod Dentofacial Orthop 2010; 137: 59097.
[37] Olive RJ. Orthodontic treatment of palatally impacted maxillary canines. Aust Orthod J 2002; 18: 64-70.

[38] Peck S, Peck L, Kataja M. Sense and nonsense regarding palatal canines. Angle Orthod 1994; 65: 99-102.

[39] Hanson MI, Barnard LW, Case JL. Tongue thrust preschool children. Part II: dental occlusal patterns. Am J Orthod 1970; 57: 1522.

[40] McConnell TL, Hoffman DL, Forbes DP, Jensen EK, Wientraub NH. Maxillary canine impaction in patients with transverse maxillary deficiency. J Dent Child 1996; 63: 190-5.

[41] Al Nimri K., Gharaibeh T. Space conditions and dental and occlusal features in patients with palatally impacted maxillary canines: aetiological study. Eur J Orthod 2005; 27: 461-5.

[42] Sambataro S, Baccetti T, Franchi L, Antonini F. Early predictive variables for upper canine impaction as derived from posteroanterior cephalograms. Angle Orthod 2005; 75: 28-34.

[43] Schindel RH, Duffy SL. Maxillary transverse discrepancies and potentially impacted canines in mixed dentition patients. Angle Orthod 2007; 77: 430-5.

[44] Basdra EK, Kiokpasoglou MN, Komposch G. Congenital tooth anomalies and malocclusion: a genetic link? Eur J Orthod 2001; 23 : 145-51.

[45] Lüdicke G, Harzer W, Tausche E. Incisor inclination--risk factor for palatally-impacted canines. J Orofac Orthop 2008; 69: 357-64.

[46] Lindauer SJ, Rubenstein LK, Hang WM, Andersen WC, Isaacson RJ. Canine impaction identified early with panoramic radiographs. J Am Dent Assoc 1992; 123: 91-7.

[47] Fernandez E, Bravo LA, Canteras M. Eruption of the permanent upper canine: a radiologic study. Am J Orthod Dentofacial Orthop 1998; 113: 414-20.

[48] Warford JH, Grandhi RK, Tira DE. Prediction of maxillary canine impaction using sectors and angular measurement. Am J Orthod Dentofacial Orthop 2003; 124: 651-55.

[49] Olive RJ. Factors influencing the non-surgical eruption of palatally impacted canines. Aust Orthod J 2005; 21: 95-101.

[50] Ricketts RM, Bench RW, Hilgers JJ, Schulhof R. An overview of computerized cephalometrics. Am J Orthod 1972; 61: 1-28.

[51] Walker L, Enciso R, Mah J. Three-dimensional localization of maxillary canines with cone-beam computed tomography. Am J Orthod Dentofacial Orthop 2005; 128: 418-23.

[52] Kokich VG. Cone-beam computed tomography: have we identified the orthodontic benefits? Am J Orthod Dentofacial Orthop 2010; 137(4 Suppl): S16.

[53] Jacobs SG. Reducing the incidence of unerupted palatally displaced canines by extraction of deciduous canines: the history and application of this procedure with some case reports. Aust Dent J 1998; 43: $20-7$.

[54] ShapiraY, Kuftinec MM. Early diagnosis and interception of potential maxillary canine impaction. J Am Dent Assoc 1998; 129: 14504.

[55] Leonardi M, Armi P, Franchi L, Baccetti T. Two interceptive approaches to palatally displaced canines: a prospective longitudinal study. Angle Orthod 2004; 74: 581-6.

[56] Baccetti T, Leonardi M, Armi PA. Randomized clinical study of two interceptive approaches to palatally displaced canines. Eur $\mathbf{J}$ Orthod 2008; 30: 381-5.

[57] Baccetti T, Mucedero M, Leonardi M, Cozza P. Interceptive treatment of palatal impaction of maxillary canines with rapid maxillary expansion: a randomized clinical trial. Am J Orthod Dentofacial Orthop 2009; 136: 657-61.

(C) Litsas and Acar; Licensee Bentham Open.

This is an open access article licensed under the terms of the Creative Commons Attribution Non-Commercial License (http://creativecommons.org/licenses/by-nc/3.0/) which permits unrestricted, non-commercial use, distribution and reproduction in any medium, provided the work is properly cited. 